\title{
ANÁLISE DA AÇÃO EDUCATIVA NAS HISTÓRIAS DE VIDA E DE FORMAÇÃO DE MULHERES EM VULNERABILIDADE SOCIAL
}

Gisela Silva Suppo ${ }^{1}$

\section{INTRODUÇÃO}

A proposição inicial parte da análise acerca de questões do conceito de gênero que ainda delineiam o papel da mulher na sociedade atual e a estreita vinculação existente com o seu papel de reprodutora.

Para compreender como ocorre o processo de vulnerabilidade social no grupo de mulheres é necessário uma compreensão do conceito de feminização da pobreza e a partir dele, dois elementos são destacados: a pobreza e a desigualdade de gênero, cada vez mais crescentes na sociedade atual.

De acordo com a Comissão Econômica para a América Latina e Caribe (CEPAL, 2000), a pobreza e exclusão atingem de forma diferenciada as mulheres. Neste cenário, o Brasil ocupa o 15 lugar em relação ao índice que mede a desigualdade de gênero na América Latina, estando à frente apenas da Guatemala.

$\mathrm{Na}$ sociedade atual encontramos fortes vestígios deixados pela sociedade da época colonial que estão presentes de forma velada em inúmeras situações onde há a prevalência de direitos do sexo masculino sobre o feminino, independentemente da condição social e econômica.

A igualdade de gênero é reconhecida desde 1948 na Declaração Universal de Direitos Humanos. Contudo, ainda, percebe-se a ocorrência de discriminação e visões estereotipadas do papel feminino, principalmente no que tange à oferta de oportunidades no mercado de trabalho e ao acesso a espaços públicos de poder.

Os movimentos feministas ocorridos na década de 70 provocaram a discussão do papel político e social da mulher além de outras questões essenciais como a necessidade de se implantar políticas públicas de gênero para assegurar a garantia de direitos, autonomia e fortalecimento das mulheres. 
O Programa das Nações Unidas para o Desenvolvimento (PNUD, 2008), iniciou um debate mundial sobre a questão de gênero que fortaleceu a discussão sobre a criação de estratégias contra a pobreza, a desigualdade social e de gênero.

A inclusão da mulher como representante do grupo familiar e beneficiária de programas sociais, pelo papel que desempenha enquanto mãe e cuidadora, não assegura uma mudança efetiva. As políticas de gênero devem ser integradas, multidirecionais, promover a geração de oportunidades e focalizar as atividades produtivas das mulheres (NOVELLINO, 2004).

Em 2000 a Organização das Nações Unidas - ONU divulgou o documento chamado "As Metas de Desenvolvimento do Milênio" que trata de um conjunto de 8 objetivos definidos pelos países membros, a serem cumpridos até 2015.

Esses objetivos provêm do Programa das Nações Unidas para o Desenvolvimento - PNUD que é o organismo internacional, ou seja, a entidade das Nações Unidas que tem por mandato promover o desenvolvimento e eliminar a pobreza no mundo

O Programa das Nações Unidas para o Desenvolvimento - PNUD dissemina as Metas de Desenvolvimento do Milênio e monitora o progresso dos países, considerando-se as especificidades nacionais.

Com o terceiro objetivo do milênio que propõe a igualdade entre os sexos e da valorização da mulher, houve o fortalecimento da discussão sobre as políticas de gênero, no Brasil.

Dessa forma, a partir de 2007 o governo brasileiro instituiu um projeto piloto chamado Programa Mulheres Mil educação, cidadania e desenvolvimento sustentável, para favorecer a autonomia, qualificação e alternativas de inserção das mulheres no mundo do trabalho.

O projeto piloto foi criado através do cumprimento de acordos bilaterais de cooperação internacional entre Brasil e Canadá e representado pelos órgãos da Secretaria de Educação Profissional Tecnológica - SETEC. A implantação deu-se nos campi dos Institutos Federais de Educação das regiões Norte e Nordeste

O Projeto foi estruturado em três eixos centrais: educação, cidadania e desenvolvimento sustentável e tem como base a inclusão social e a redução das desigualdades sociais. 
A Metodologia utilizada foi inspirada nos modelos de acesso dos colleges Canadenses denominada de Avaliação e Reconhecimento de Aprendizagem Prévia - ARAP que garante a capacitação profissional para populações desfavorecidas.

Dado aos resultados positivos que foram obtidos com o projeto piloto, a partir de 2012 a experiência foi estendida como Programa a diferentes regiões do país, sob a responsabilidade dos Institutos Federais locais. A responsabilidade de ofertar o Programa Mulheres Mil em âmbito nacional ficou sob a responsabilidade dos Institutos Federais por sua representatividade nas diversas regiões do país.

A execução do Programa tem início com o registro de dados do públicoalvo e de sua comunidade por meio da especificação de metas e necessidades reais (demandas pessoais, grupais e institucionais) de modo a mapear e sistematizar os saberes já existentes, constituindo-se como fonte de referência na construção de itinerários formativos mediante o reconhecimento formal dos saberes nos moldes da Rede Nacional de Certificação - CERTIFIC. Dessa forma, não há exigência de escolarização mínima para matricular-se em um curso do Programa Mulheres Mil. A triagem é feita pela análise do questionário e da entrevista, geralmente em parceria com o Centro de Referência de Assistência Social-CRAS, unidades estatais responsáveis pela oferta de serviços continuados de proteção social.

O principal objetivo do Programa é o de garantir a inclusão social, por meio da oferta de formação voltada para a autonomia e a criação de alternativas para a inserção no mundo do trabalho, para que mulheres consigam melhorar a qualidade de suas vidas e das de suas comunidades.

Em Mato Grosso do Sul, o Instituto Federal de Educação, Ciência e Tecnologia de Mato Grosso do Sul - IFMS iniciou a oferta das primeiras turmas em 2012.

O interesse pelo assunto deu-se pela peculiaridade do Programa e pela possibilidade de formar mulheres em vulnerabilidade social que dificilmente teriam acesso a uma formação profissional, dada às exigências estabelecidas para o ingresso na maior parte dos cursos existentes.

Para a realização da pesquisa foram adotados os pressupostos da abordagem qualitativa pela natureza do objeto pesquisado. A metodologia qualitativa preocupa-se em analisar e interpretar aspectos mais profundos, descrevendo a complexidade do comportamento humano (MARCONI; LAKATOS,2004). 
Foram feitas entrevistas com um grupo de egressas do curso Artesão em Cerâmica do Campus Coxim do IFMS. As histórias de vida foram gravadas e após serem transcritas serão levantadas as mudanças e as possibilidades que a formação profissional recebida proporcionou em suas vidas.

As mudanças percebidas no grupo pesquisado foram notadas de forma clara na questão do empoderamento. O conceito de empoderamento percebido nesse grupo de mulheres ficou evidente e tornou-se um forte elemento de análise dessa pesquisa pelas narrações que foram feitas.

\begin{abstract}
O empoderamento das mulheres traz uma nova concepção de poder, assumindo formas democráticas, construindo novos mecanismos de responsabilidades coletivas, de tomada de decisões e responsabilidades compartidas. É também um desafio às relações patriarcais, em relação ao poder dominante do homem e a manutenção dos seus privilégios de gênero, é uma mudança na dominação tradicional dos homens sobre as mulheres, garantindo-lhes a autonomia no que se refere ao controle dos seus corpos, da sua sexualidade, do seu direito de ir e vir. (COSTA, 1998, p.10).
\end{abstract}

Utilizamos como parâmetro para análise do empoderamento: a construção de uma autoimagem e confiança positiva; o desenvolvimento da habilidade para pensar criticamente; a construção da coesão de grupo e a promoção da tomada de decisões (STROMQUIST, 1997).

A confirmação do empoderamento pode ser feita pela descrição voluntária de fatos ocorridos tanto na vida pessoal como familiar, ocorridos no período em que ainda estavam fazendo o curso, na conclusão com a materialização da conquista ao receber o certificado de artesão em cerâmica.

O entusiasmo com que descreveram o sentimento de vender as peças produzidas, a transformação da argila em um objeto, as possibilidades de aprenderem novas técnicas em outros cursos para melhorar a qualidade das peças, foi também um traço comum observado.

O incentivo do aumento na renda familiar foi o primeiro motivo que as levou a buscar uma formação profissional, mas disseram ter encontrado ricos ensinamentos. Aprenderam e debateram sobre assuntos importantes como: a saúde e os direitos da mulher, informática, empreendedorismo entre outros que foram trabalhados no curso.

A equipe de apoio envolvendo professores, coordenadores, direção e voluntários foi a condição essencial para a obtenção de resultados positivos. $O$ 
entendimento da necessidade de adaptação metodológica para tornar possível o aprendizado, com as aulas práticas, as dinâmicas de vida e o acompanhamento dado no início da inserção profissional foi fundamental para o sucesso dessa experiência no Campus Coxim.

Atualmente a prefeitura local cedeu um prédio para que funcionasse a Associação Art's Mil, onde as egressas se revezam em escalas de trabalho e produzem suas peças.

Uma política pública de gênero que atingiu de maneira efetiva o públicoalvo a que se destina, mas que precisa ter as suas peculiaridades asseguradas para que o Programa não se descaracterize.

A amplitude do efeito que a ação educativa atingiu nas vidas dessas mulheres não poderá ser mensurada, mas se confirmará pela dimensão que ocupou em suas vidas.

\begin{abstract}
Todo conhecimento deve conter um mínimo de contrassenso, como os antigos padrões de tapete ou de frisos ornamentais, onde sempre se pode descobrir, nalgum ponto, um desvio insignificante de seu curso normal. Em outras palavras: o decisivo não é o prosseguimento de conhecimento em conhecimento, mas o salto que se dá em cada um deles. É a marca imperceptível da autenticidade que os distingue de todos os objetos em série fabricados segundo um padrão. (BENJAMIN, 1993, p.10).
\end{abstract}

Uma vez abertas as janelas da percepção trazidas pelo conhecimento, nunca mais poderá o homem enxergar o mundo da mesma forma.

Essa é a grandiosidade do alcance de novos aprendizados.

\title{
REFERÊNCIAS
}

BENJAMIN, Walter. O Conceito de Crítica de Arte no Romantismo Alemão. São Paulo: Editora da Universidade de São Paulo/lluminuras, 1993.

BRASIL. Programa nacional mulheres mil: Educação, Cidadania e Desenvolvimento Sustentável. Disponível em: http://portal.mec.gov.br/dmdocuments/planonacional_politicamulheres.pdf. Acesso em: 08 abr.2016.

CEPAL, Comissão Econômica para a América Latina. The Equity Gap: a second assessment. Second Regional Conference in Follow-up to the Worls Summit for Social Development, 2000.

COSTA, A. A. As donas no poder. Mulher e política na Bahia. Salvador: NEIM/UFBA - Assembléia Legislativa da Bahia,1998. 
MARCONI, M.A; LAKATOS, E.M. Técnicas de pesquisa. São Paulo: Atlas, 2004.

MINISTÉRIO DA EDUCAÇÃO. Secretaria de Educação Técnica e Tecnológica. Disponível em: http://portal.mec.gov.br/setec-secretaria-de-educacao-profissionaletecnologica/programas. Acesso em: 20/03/2016.

NOVELLINO, M. S. F. Os estudos sobre feminização da pobreza e políticas públicas para mulheres. In: XIV ENCONTRO DA ABEP, 2004, Caxambú, MG. 2004.

PROGRAMA DAS NAÇÕES UNIDAS PARA O DESENVOLVIMENTO. http:// pndu.org.br. Acesso em: 15 mar.2016.

STROMQUIST, N. La búsqueda del empoderamiento: em qué puede contribuir el campo de la educación. In: LEÓN, Magdalena (Comp.). Poder y empoderamento de las mujeres. Santafé de Bogotá, Colômbia: TM Editores, 1997. 